\title{
Small Private Online Course Based Flipped Classroom Approach for Supporting Undergraduate Medical Technology Students on Immunology Study
}

\author{
Somying Loharungsikul \\ Faculty of Medical Technology Mahidol University \\ Kawitsara Eumbunnapong \\ Siriraj Hospital Mahidol University \\ Prachyanun Nilsook \\ King Mongkut's University of Technology North Bangkok \\ Patcharin Panjaburee ( $\sim$ patcharin.pan@mahidol.edu ) \\ Institute for Innovative Learning Mahidol University
}

\section{Research Article}

Keywords: Medical Technology education, Higher education, Instructional strategies, Online learning, Blended learning

Posted Date: January 19th, 2022

DOl: https://doi.org/10.21203/rs.3.rs-1210422/v1

License: (a) (i) This work is licensed under a Creative Commons Attribution 4.0 International License. Read Full License 


\section{Abstract \\ Background}

Small private online course (SPOC) combined with the flipped classroomis established in higher education as an innovative tool for improvingstudents' learning efficiency. To investigate the impact of the SPOC-based flipped classroomapproach, we implemented this reform pedagogy on anbasic immunology course for medical technology students.

\section{Methods}

The undergraduate medical technology students of Mahidol Universityenrolled SPOC platform for self-active online learning in the detection of immunological reactions and applications and then attended the face-to-face teaching activity in the classroom. The learning improvement was evaluated by conceptual test (CT)throughout this reform curriculum. Furthermore, students were required to fill in a questionnaire to reflect their perceptions and motivations.

\section{Results}

A significant increase in the overall score data of the mid- and the post-conceptual test was found. The result indicated that SPOC based flipped classroom method improved university students'learning knowledge in the detection of immunology reactions and applications. From the perception and motivation questionnaires, students had a positive attitude in which they had more practical and meaningful activities with this reform course. Students revealed that better interest and enjoyment with less anxiety could induce them to connect the topic to their career in the future.

\section{Conclusions}

TheSPOC-based flipped classroom approach effectively encouraged students'learning improvement and positively impacted their learning perceptions and motivations on fundamental immunology study in the field of medical technology education.

\section{Background}

The flipped classroom is a blended learning approach where students learn basic content independently via online video or e-learning before class time and subsequently join the face-to-face time for more active learning strategies using reflection, problem-based discussions, or case solving[1]. The curricular reform of flipped classroom model has been shown to promote positive learning outcomes and student participation than the traditional classroom [2, 3]. Several healthcare-professional schoolshave widely accepted the flipped classroom model to build their educational competency. Most students showed high satisfaction with medical education when the flipped classroom method was implemented in gynaecologic oncology, ophthalmology, pharmacology, and endocrinology studies. The medical student strongly agreed that this learning method could promote their learning motivation, enhance communication skills, and improve clinical thinking compared to conventional teaching [4-6].In addition, 
the students, who followed the flipped classroom activities, had a deep understanding of the course materials leading to thesignificant improvement of the testing scores[3, 6].

Since the high quality of online learning platform was established in open education, small private online courses (SPOCs)is a hybrid model for integrating online learning with the traditional classroom on a small scale. This specific character of SPOCs allows it to like broadly accessible learning that can reduce the high drop-off rate of students within the first week of the course [7]. However, SPOCs are commonly used to support face-to-face classes and can also be applied with flipped classroom method. Students access videos and reading materials in the SPOC. Then, they participate in the classroom for discussion and problem solving under the guidance of teachers $[8,9]$. The SPOC-based flipped classroom model was recently progressively implemented in health science education. Post-graduate medical educators used SPOC video technology and web conferencing software for an integrated case conference and in-depth neuroscience discussion from across the diverse location in psychiatry training programs. The feedback from participants for this implementation also showed largely positive [10]. The investigation of this particular teaching mode in physiology course showed the improvement of learning efficiency and a deep understanding of knowledge for clinical undergraduate students, which were reflected by the higher examination scores compared to the students in lecture-based learning. The differences in their scores were affected by video-based preview in the SPOC model [11]. The SPOC-based flipped classroom approach for radiology learning significantly showed the performance change between pre- and post-tests among medical students. The highest improvement was found in the low-achieving students when they received the video-based lectures, while the high-achieving students reflected relaxation when participating in the face-to-faceactivities [12].In addition, the application of SPOC-based flipped classrooms in clinical hematology laboratory teaching promotes students' confidence in practice and increases their laboratory skills [13].

Medical technology is a professional laboratory worker who expert in human sample analysis for clinical diagnosis. Medical technology education aims to teach laboratory testing knowledge, including principles, methods, reading, and interpretation of the test results. Traditionally, medical laboratory courses begin with a short lecture given by teachers, which strictly complies with the laboratory manual. Then, students are divided into small groups and perform the experimental sessions following the instructions' manual step by step under the supervision of teachers.Many students finish their laboratory courses without fully understanding the principles behind the experiments [14]. Although, there is limited literature on the efficacy of blended learning in medical technology education. Research suggested that flipped classroom strategy significantly improves medical technology students' learning capacity in evidence-based medicine training. Compared to traditional classrooms, most students showed positive attitudes and views on this reform class [15]. Scholars suggested that the integration of flipped classrooms and SPOC on clinical hematology laboratory teaching can be improved the learning efficacy of undergraduate medical technology students both in theoretical examination and experimental tests [13]. However, there is shortcoming researchon the curricular reform in immunology study. To continue the entire curricular reform of immunology topic, undergraduate medical technology students'learning performance needs to be empirically investigated to spotlight the implementation of SPOC-based flipped classroom method inmedical technology education.Therefore, this study empirically evaluated the impact of the SPOC-based flipped classroom method on students'actual course performance by measuring learning improvement and course timing in the actual university setting. Another purpose of this study was to investigate students' learning perceptions and motivations about the SPOC-based flipped classroom. This study aimed to answer the research questions (RQ) as follows: 
RQ1:How did students in the SPOC-based flipped classroom method improve their immunology learning achievement?

RQ2:As expressed in their post-learning, what are students' learning perceptions and motivations through the SPOC-based flipped classroom method?

RQ3:What are the relationships between students'learning perceptions and motivations through the SPOC-based flipped classroom method?

\section{Methods}

\section{Study design and participant descriptions}

A department of clinical microbiology and applied technology, Faculty of Medical Technology, Mahidol University of Thailand, was conducted to study students'learning improvement, perceptions, and motivations about the topic detection of immunological reactions and applications in a basic immunology course. This topic was chosen for implementingthe curriculum reform of the SPOC-based flipped classroom because the basic knowledge obtained from this topic is useful for the students to perform the clinical laboratory testing. The university supports the development and implementation of SPOC across usual university learning settings.A batch of 81 medical technology students applied in the basic immunology curriculum was recruited to participatein this study. Individual students agreed to participate by signing the informed consent according to the guidelines of brief descriptions from the Ethics Committee of the Central Institutional Review Board, Mahidol University, Thailand(MU-CIRB 2019/158.0710).All participants had no previous experience in the SPOC-based flipped classroom method before participating in this study.

\section{Spoc-based Flipped Classroom The development of SPOC}

A small private online course (SPOC)was created on the online course platform of Mahidol University (https://mux.mahidol.ac.th/courses/course-v1:MU-MT+MTMI307+2019/course/) as an alternative tool. SPOC was aimed to serve as a self-learning platform with abundant online learning material and a clear knowledge structure for participants in which they can find the syllabus, teaching plan, courseware, teaching documents,and video (Fig. 1).

SPOC covered six topics designed to comply with the syllabus of traditional lecture and was created into a video following the principle of "simple and practical". Individual topics composed of pre-test, learning contents, and posttest allowed self-active learning [16].The learning contents consisted of 5 parts, including introduction, principle, materials and procedures, result and interpretation, and examples in the clinical application conducted to learn every knowledge point for basic immunological technique curriculum systematically (Table 1). SPOC was the personalized platform where participants could organize their own learning pace. They could stop or rewatch videos, which were especially pertinent for difficult topics, or students could accelerate through a video if they were familiar with the subject. To create active online communication, participants could then post their questions on the SPOC discussion board, which were directly answered by the professional instructors responsible for the course. 
Table 1

SPOC ofthe detection of immunological reactions and applications in a basic immunology course

Topics Learning Materials

\section{Agglutination, precipitation, and} immunoelectrophoresis

- Agglutination reaction and its application

- Principle of precipitation technique

- Serum protein electrophoresis and application

- Immunoelectrophoresis and interpretation

- Immunofixation and application in clinical used

\section{Neutralization and complement fixation}

-Principle and application

\section{Immunohistochemistry and Immunocytochemistry staining}

-Principle, Lab demonstration, and application of immunofluorescence technique

-Principle of immunoperoxidase and its application

\section{Enzyme-linked immunosorbent assay (ELISA)}

-Principle and procedures

-Types of ELISA and applications

\section{Immunoblotting technique}

-Principle, Lab demonstration, and application

\section{Flow Cytometry}

- Principle, Lab demonstration, and application
Quizzes, Lesson plan, VDO, Laboratory protocol, hand-out, Discussion broad
Quizzes, Lesson plan, VDO, hand-out, Teaching document, Discussion broad

Quizzes, Lesson plan, VDO, hand-out, Teaching document, Discussion broad

\section{Setting learning activities of SPOC-based flipped classroom}

The instructional design of the SPOC-based flipped classroom was established according to self-active learning on the SPOC platform and face-to-face teaching activity in the classroom (Fig. 2).To organize the pre-class tasks, all participants enrolled SPOC course on the online platform using their individual MU login. Before starting self-active learning, participants were required to complete a pre-test on the SPOC course. Instructors released the teaching plan one week to inform the learning objectives and enable effective self-learning. Participants could arrange their learning process on the SPOC course by watching infographic videos, reading teaching documents, and completing the post-test related to the learning contents in each topic. In classroom teaching time, all participants were randomly divided into groups and participated in a face-to-face laboratory activity with instructors (ratio of participants and instructors = 10:1 in each group). Each group was assigned a question or made a discussion. The instructors were only organizers and directors for learning: their roles were to guide students to find answers to problems by themselves and inspire students' enthusiasm for information. The ability extension after the SPOC- 
based flipped classroom module was evaluated using the course examination. The student self-assessment form was used to evaluate this learning module's perceptions.

\section{Data Collections}

In this study, a repeated measures research design was employed to examine the learning improvement of the student participants during the course. The data collection procedures along with the timing of SPOC and face-toface learning modes was presented (Fig. 3).At the beginning of SPOC, the participants took a conceptual test on the detection of immunological reactions and applications topic.It was regarded as the pre-test data, meaning that the participants were elicited their prior knowledge in the detection of immunological reactions and applications topic before participating in theSPOC-based learning flipped classroom method.Around six weeks later, at the end of SPOC learning, the participants respond to the conceptual test again, as the mid-test data.

Similarly, around one weeklater, at the end of face-to-face learning, the participants respond to the conceptual test again, as the post-test data. That is to say, the mid-, and post-test data reflected the participants' knowledge in the detection of immunological reactions and applications topic with the SPOC-based flipped classroom of this study. After the course ended, the students took questionnaires of learning perceptions and motivations about the SPOCbased flipped classroom method, which lasted 60 minutes.

To answer the research questions of this study, conceptual tests, and learning perception and motivation questionnaires were administered as the data sources in this study.

\section{Conceptual test}

The pre-, mid-, and post-conceptual tests were constructed following the course learning outcome and were verified by professional instructors responsible for the course. The tests contained 85multiple-choice items ( 1 score for each correct answer)and 31open-ended questions (1 score for each correct answer); therefore, the test's total score was 116 by covering six sub-topics of the detection of immunological reactions and applications topic. That is to say, the pre-test aimed to evaluate the students'prior knowledge of the detection of immunological reactions and applications.On the other hand, the mid- and post-tests aimed to measure the students'knowledge improvement after participating in SPOC and face-to-face learning activities.

\section{Immunology learning perception questionnaire}

The immunology learning perception questionnaire aimed to survey the students' perceptions after learning in the SPOC-based flipped classroom method on the detection of immunological reactions and applications topic.It was adopted from the technology acceptance questionnaire and translated to Thai by researchers[17]. A total of 12 items with a five-pointLikert rating scale ranging from 1 "strongly disagree" to 5 "strongly agree"was used to cover four dimensions (three items per each dimension), including Perceived Usefulness (PU), Perceived Ease of Use (PE), Attitude (AT), and Behavior Intention (BI).PU represents that the student beliefs using theSPOC-based flipped classroom method would help them improve knowledge of detection of immunological reactions and applications.PE aims to elicit the students' belief that participating in learning activities in the SPOC-based flipped classroom would be easy and withouteffort to use.AT aims to measure the students'positive or negativebehavior when participating in learning activities using the SPOC-based flipped classroom method.BI represents that the student would accept to use the SPOC-based flipped classroom in the other learning topics further. The Cronbach's 
alpha value of the questionnaire in the Thai version was 0.92 , which is reliable.Moreover, the composite reliability values for the PU, PE, AT, and BI were $0.92,0.80,0.76$, and 0.81 , respectively, showing good internal consistency of each dimension.

\section{Immunology motivation questionnaire}

The immunology learning motivation questionnaire aimed to investigate the students'motivations after learning in the SPOC-based flipped classroom method on the detection of immunological reactions and applications topic.It was adopted from the science motivation questionnaire and translated to Thai by researchers [18].A total of 30 items with a five-point Likert rating scale ranging from 1 "strongly disagree" to 5 "strongly agree" was used to cover six dimensions (five items per dimension), including Intrinsic Motivation (IM), Extrinsic Motivation (EM), Career Motivation (CM), Self-Determination (SDT), Self-Efficacy (SEF), and Assessment Anxiety(AA). IM refers to the students'feelings about interesting, meaningful, and enjoyabledetection of immunological reactions and applications learning activities in the SPOC-based flipped classroom.EM refers to receiving a good performance inthe detection of immunological reactions and applications.CM refers to engaging the students to achieve performance goals in a career path by detecting immunological reactions and applications from the learning activities in the SPOC-based flipped classroom.SDT refers to how much the students take effort, time-spend, and wellpreparedness to learn detection of immunological reactions and applications in the SPOC-based flipped classroom.SEF asked the students about their confidence in acquiring knowledge, understanding, and performing detection of immunological reactions and application tasksin the SPOC-based flipped classroom.AA aims to elicit the students' nervousness about reporting the results of the detection of immunological reactions and applications assessment.The questionnaire's internal consistencies of the subscales by Cronbach's alphas of IM, EM, CM, SDT, SEF, and AA were $0.71,0.54,0.74,0.60,0.89$, and 0.75 , respectively. The Cronbach's alpha value for the Thai version of the motivation questionnaire was 0.87 , implying good reliability for the survey.

\section{Results}

\section{Results of the students' learning improvement of detection of immunological reaction topic}

Regarding the pre-, mid-, and post-test data, the mean scores of the detection of immunological reactions and applications learning, the $F$-values, and effect sizes are presented (Table 2).A significant improvement was found across the pre-, mid-, and post-CT for six sub-topics of the detection of immunological reactions and applications topic and overall score data. That is to say, pairwise comparisons with Post hoc tests using the Bonferroni correction indicated that the students' mid-test mean scores had been increased and their post-testmean scores had been increased, which were statistically significant difference to pre-test mean scores $(p<0.05)$. However, they exhibited a slight improvement in knowledge of the the detection of immunological reactions and applications topic from mid-test to post-test mean scores, which was not statistically significant $(p>0.05)$. 
Table 2

Results of repeated-measures and pairwise comparisons across pre-, mid-, and post-tests

\begin{tabular}{|c|c|c|c|c|c|c|}
\hline \multirow[t]{2}{*}{ Topics } & Pre-test & Mid-test & Post-test & \multirow[t]{2}{*}{$F(1,48)$} & \multirow[t]{2}{*}{$\eta^{2}$} & \multirow{2}{*}{$\begin{array}{l}\text { Pairwise } \\
\text { comparison }\end{array}$} \\
\hline & $M(S D)$ & $M(S D)$ & $M(S D)$ & & & \\
\hline \multirow{2}{*}{$\begin{array}{l}\text { Agglutination, } \\
\text { Precipitation and } \\
\text { Immunoelectrophoresis }\end{array}$} & $8.35(3.345)$ & 18.04(3.272) & $18.51(2.256)$ & 217.524 & 0.82 & Pre $<$ Mid $^{\star}$ \\
\hline & & & & & & Pre $<$ Post* \\
\hline \multirow{2}{*}{$\begin{array}{l}\text { Neutralization and } \\
\text { Complement Fixation }\end{array}$} & $4.85(1.801)$ & $9.65(1.609)$ & $9.78(1.413)$ & 145.460 & 0.76 & Pre $<$ Mid* \\
\hline & & & & & & Pre $<$ Post $^{*}$ \\
\hline \multirow{2}{*}{$\begin{array}{l}\text { Immunohistochemistry } \\
\text { or } \\
\text { Immunocytochemistry } \\
\text { Staining }\end{array}$} & $6.06(2.536)$ & $12.55(2.072)$ & $12.29(1.708)$ & 146.163 & 0.75 & Pre $<$ Mid* \\
\hline & & & & & & Pre $<$ Post* \\
\hline Enzyme- & $6.42(2.071)$ & $8.73(1.747)$ & $9.23(1.207)$ & 40.980 & 0.47 & $\operatorname{Pre}<\mathrm{Mid}^{*}$ \\
\hline $\begin{array}{l}\text { Linked Immunosorbent } \\
\text { Assay (ELISA) }\end{array}$ & & & & & & Pre $<$ Post* \\
\hline \multirow{2}{*}{$\begin{array}{l}\text { Immunoblotting } \\
\text { Technique }\end{array}$} & $3.68(1.270)$ & $6.38(0.990)$ & $6.06(1.092)$ & 89.179 & 0.66 & Pre $<$ Mid* \\
\hline & & & & & & Pre $<$ Post* \\
\hline \multirow[t]{2}{*}{ Flow Cytometry } & $2.73(1.300)$ & $5.67(1.655)$ & $5.96(1.368)$ & 77.222 & 0.62 & Pre $<$ Mid* $^{*}$ \\
\hline & & & & & & Pre $<$ Post $*$ \\
\hline \multirow[t]{2}{*}{ Overall } & 45.18(12.998) & $86.98(13.201)$ & 87.96(10.364) & 238.348 & 0.83 & Pre $<$ Mid* \\
\hline & & & & & & Pre $<$ Post $^{\star}$ \\
\hline
\end{tabular}

Obviously, the repeated measures analysis also showed whether the students through SPOC and face-to-face learning activities increased their scores on the pre-, mid-, and post-tests data(Fig. 4).It was found that the students increased their scores among the pre-, mid-, to post-tests of thedetection of immunological reactionsand applicationstopic; interestingly, they showed significantly increased their mid-test mean scores and post-test mean scores to pre-test mean scores. Therefore, it implies that a long-term SPOC-based flipped learning activity (7 weeks) elicits a statistically significant improvement in the detection of the immunological reactions and applicationstopic.

\section{Results of the students' learning perceptions about the SPOC- based flipped classroom}

Regarding a series of intervals for a five-point Likert scale, when analyzing the learning perception questionnaire, descriptive statistics are used to describe mean scores, where 1-1.79 represents "strongly disagree", 1.80-2.59 represents "disagree", 2.60-3.39 represents "neutral", 3.40-4.19 represents "agree", and 4.20-5.00 represent"strongly agree". Therefore, the students were asked to respond to a learning perception questionnaire to understand their perceptions of the SPOC-based flipped learning activities. Learning perception is related to perceived usefulness, 
ease of use, attitude, andbehavior intention. The descriptive data on the students' perceptions of learning in the SPOC-based flipped classroom learning activities was presented (Table 3). They agreed that the SPOC-based flipped learning activities could support and facilitate them in developing knowledge of the detection of the immunological reactions and applications topic in the basic immunology course.

Table 3

The descriptive data of students' learning perceptions

\begin{tabular}{|llll|}
\hline Learning perceptions & $\boldsymbol{M}$ & $\boldsymbol{S D}$ & Interpretation \\
\hline Perceived Usefulness (PU) & 4.00 & 2.057 & Agree \\
\hline Perceived Ease of Use (PE) & 3.98 & 1.716 & Agree \\
\hline Attitude (AT) & 3.76 & 1.983 & Agree \\
\hline Behaviour Intention (BI) & 3.72 & 1.955 & Agree \\
\hline
\end{tabular}

\section{Results of the students' learning motivations about the SPOC- based flipped classroom}

Similar to the learning perception questionnaire, when analyzing the learning motivation questionnaire, descriptive statistics are used to describe mean scores, where 1-1.79 represents "strongly disagree", 1.80-2.59 represents "disagree", 2.60-3.39 represents "neutral", 3.40-4.19 represents "agree", and 4.20-5.00 represent "strongly agree". That is to say, to understand the students' learning motivationsabout the SPOC-based flipped learning activities,they were asked to respond to a learning motivation questionnaire.The learning motivation is related tointrinsic motivation, extrinsic motivation, career motivation, self-determination, self-efficacy, and assessment anxiety.The descriptive data on the students' learning motivations after learning in the SPOC-based flipped classroom method was also presented (Table 4). They agreed that the SPOC-based flipped learning activities could motivate them to develop knowledge of the detection of immunological reactionsand applicationstopic in the basic immunology course.Moreover, they had lessbasic immunology assessment anxiety whenthey followed the SPOCbased flipped classroom learning activities.

Table 4

The descriptive data of students' learning motivations

\begin{tabular}{|llll|}
\hline Learning motivations & $\boldsymbol{M}$ & SD & Interpretation \\
\hline Intrinsic Motivation (IM) & 3.62 & 2.602 & Agree \\
\hline Extrinsic Motivation (EM) & 3.92 & 2.236 & Agree \\
\hline Career Motivation (CM) & 3.83 & 2.453 & Agree \\
\hline Self-Determination (SDT) & 3.72 & 2.150 & Agree \\
\hline Self-Efficacy (SEF) & 3.16 & 3.010 & Neutral \\
\hline Assessment Anxiety (AA) & 1.41 & 3.489 & Strongly Disagree \\
\hline
\end{tabular}




\section{Results of the students'learning perceptions and motivations}

Regarding students'improvement across the pre-, mid-, and post-test means scores, and their positive response to learning perceptions and motivations about the SPOC-based flipped classroom method, those dimensions of learning perceptions and motivations have been affectingtheir self-pace learning in the SPOC and active learning in the in-class learning activities.Furthermore, among those dimensions related to students' attitudinal factors to improve their learning in the detection of immunological reactionsand applicationstopic, they may be connected to strengthen further why students improve learning in the SPOC-based flipped classroom learning activities. Therefore, the results led this study to analyze further how the students' learning perceptions are connected to their motivations.

The results of the correlations between learning perceptions and learning motivations have shown (Table 5). The Pearson's coefficient of each pair between learning perceptions and motivations was tested.Positive correlations were found among the dimensions, i.e., PU, PE, AT, BI, IM, EM, CM, SDT, and SEF.Negative correlations were found among PU, PE, AT, BI, and AA.AT and IM(r=0.515, $p<0.01)$, and PU and CM(r=0.452, $p<.01)$ tended to have larger positive significant correlations than the others did.The results mean that students positively felt about learning activities in the SPOC-based flipped classroom when they had been intrinsically provided motivating with the somewhat interesting or enjoyable learning environment in such classroom and vice versa.Moreover, students found the usefulness of learning activities in the SPOC-based flipped classroom when individuals connected to the medical technology/healthcare-professional career and vice versa.

Interestingly, PU and AA ( $r=-0.254, p<.05)$ tended to have the most considerable negative significant correlation than the others did. That is to say;students had high perceptions about the usefulness of learning activities in the SPOC-based flipped classroom to learn detection of immunological reactions and applications; they were less nervous or anxious about the assessment of the basic immunology course.

Table 5

Correlations among learning perceptions and motivations

\begin{tabular}{|c|c|c|c|c|}
\hline Dimension & PU & PE & AT & BI \\
\hline IM & $0.431^{\star *}$ & $0.383^{\star *}$ & $0.515^{\star \star}$ & $0.440 * \star$ \\
\hline EM & $0.321 * \star$ & $0.294^{\star}$ & $0.349 * *$ & $0.356 * *$ \\
\hline CM & $0.452 * \star$ & $0.365^{\star \star}$ & $0.439 * \star$ & $0.344^{* *}$ \\
\hline SDT & 0.194 & 0.218 & $0.334^{\star \star}$ & $0.409 * *$ \\
\hline SEF & $0.245^{\star}$ & 0.136 & $0.390 * \star$ & $0.307 * \star$ \\
\hline AA & $-0.254^{\star}$ & -0.204 & -0.093 & -0.192 \\
\hline \multicolumn{5}{|c|}{ ** Correlation is significant at the 0.01 level } \\
\hline \multicolumn{5}{|c|}{ * Correlation is significant at the 0.05 level } \\
\hline
\end{tabular}

\section{Discussion}

This study presents an immunology learning instruction implemented by a SPOC-based flipped classroom. It improves university students' learning knowledge in the detection of immunological reactions and applications and 
reflects their learning perceptions, motivations, and correlations through the proposed learning method.There are three positive results related to each research question. The results led to the originality of and could be a reference of the flipped classroom with technology-assisted learning as SPOC to the effective learning environment of the detection of immunological reactions and applicationsin a basic immunology course.

Regarding the first research question (RQ1), the instruction significantly improved the students' knowledge, with large effect size, as indicated by Table 2 and Fig. 3. That is to say, the results across pre-, mid-, and post-tests indicated knowledge improvement during SPOC and face-to-face in-class learning activities with a large effect size.Analysis of the conceptual tests suggested that the SPOC and face-to-face in-class learning activities in the proposed SPOC-based flipped classroom with a long-term activity were the main sources of students' improvement of immunology knowledge. Our results confirmed the grounded theory of blended learning, raising the possibility that the implementation of SPOC and face-to-face in-class learning activities provided the opportunity for students to explore the detection of immunological reactions and applications [19].Phenomenawith related learning material provided in SPOC across out-of-class learning activities could enhancestudents'learning capacity by increasing the mid- and post-test examination scores. This result might be because the SPOC platform is designed for a specific audience and therefore has a greater capacity to adapt to the interested needs[20,21]. Especially, the online videos on SPOC could allow students to organize their learning abilities and preferences in which they were no longer restricted by the limited class hours and environments [22].In addition, face-to-face in-class learning activities emphasized laboratory demonstration, active exploration in the laboratory, and group discussions needed to use and apply a foundation of knowledge from SPOC to perform and complete the tasks in the laboratory environment. These learning activities might help explain why there was a significant improvement in the students'knowledge of the detection of immunological reactions and applications.Such laying down the foundation of knowledge to the advancement of detection of immunological reactionsand applicationsbased on the flipped classroom approach were thus introduced in the SPOC-based flipped classroom process. The students had to bring essential knowledge from learning materials provided in the SPOC to complete tasks in the in-class learning environment.This study shows that pedagogical step-by-step of the flipped classroom approach was used for acquiring knowledge from out-of-class learning and apply such knowledge for solving a particular task and represents an improvement of students'knowledge in the in-class learning activities, where they were situated to be active in the flipped classroom perspective $[23,24]$. These findings imply that long-term activities, which were set by laying down the foundation of knowledge to advanced knowledge with the support of relevant learning materials provided by SPOC, could be a strong point in face-to-face in-class learning activities to ensure a continuous improvement in all contents related to the immunology.Notably, suchenhancement in learning outcomeof SPOCbased flipped classroom approachis in line with the finding on the learning improvement of undergraduate students in physiology course [11] and their powerfulapplication in the basic medical course and histopathology learningduring the COVID-19 pandemic $[25,26]$.

Regarding the second and third research questions (RQ2 and RQ3), the overall results in our study indicated that the SPOC-based flipped classroom method showed positive perceptions and motivations for students to learn the detection of immunological reactions and applications topic in the basic immunology course (Tables 3 and 4 ). This finding confirmed the efficacy of the SPOC-based flipped classroom modelthat students appreciate and have positive attitudes toward this reformpedagogiesin higher education[8, 27].Interestingly, the results indicated that the more practical and meaningful activities in SPOC and face-to-face in-class students receive, the better interest and enjoyment with less anxiety they present to further connect the topic to their career(Table 5).In other words, the students could improve their immunology learning with useful functions in the SPOC-based flipped classroom

Page $11 / 21$ 
method.The possible explanations for these learning perceptions and motivations are that the instructional approach of SPOC in the detection of immunological reactions and applicationis well designedandfacilitatesselflearning to assist knowledge application and problem-solving. The impact of well-prepared contentsof SPOC would be even more significantforincreasinglearning outcome of students and motivatingthem to enjoy the in-class activities, as the previous demonstration that a well-structured online course combined with flipped classroom increased positive perception and promoted active participation through practical activities in the classroom [28]. In addition, weprovided several learning materials and strategies, including VDO, worksheet, laboratory demonstration, active exploration, and group discussion for SPOC-based flipped classroom implementation in thisstudybecausethe interaction between students and lecturers of the course is an important factoraffecting thestudents'perceptions and attitudesduring this reform approach [29]. The out-of-class lecturers' activities are mainly devoted to answering questions of students submitted via online discussion forums or other communication channels. During the in-class learning activities, lecturers arethe key person to facilitate students' learning process by giving guidance and supportingthemin developinghigh order thinking skills inan immunology learning course.It may be speculated that the strongpositive correlation between students'learning perceptions and motivation found in our studies could be harmonized bystudents bringing fundamental knowledge gainedfrom the technological materialestablished in the SPOCto connect concrete knowledge in the in-class active learning environment. This study could significantly enhancement the immunology classroom more completely.Moreover, the correlations among learning perceptions and motivations can be discussed by referring to the learning motivation theory.The learning materials provided in the SPOC synchronized face-to-face in-class learning tasks can motivate the students in having more enjoyment to learn and connection of medical technology/healthcareprofessional career, leading to less anxiety about the immunology assessment [18].

The findings in this study regarding the high effect size of immunology learning improvement, perceptions, and motivations of students in the SPOC-based flipped classroom method were consistent with studies showing that proper use of online learning/SPOC and flipped classroom established both cognitive and affective domains, such as knowledge, comprehension, skills, and attitudes [30].Furthermore, the overall resultsofthis study confirmed the success of SPOC-based flipped classroom implementation on the detection of immunological reactions and applications topicof a basic immunology course. The resultscomplywith the previous studies on the effectiveness of clinical hematology laboratory teaching using the combination of SPOC with flipped classroom [13], and with the results of the blended learning of basic medical laboratory course that improves medical students'abilities in self-learning, understanding, and problem-solving abilities [31].However, this study showed positive results of students'learning improvement, perceptions, and motivations on immunology study.Some concerns about this implementation include (i) this is the first time medical technology students participate in SPOC-based flipped classroom mode ina basic immunology course. Most Thai students are not familiar with self-online learning.This study provided them with various kinds of learning materials inside the SPOC platform that might be suitable and appropriate for individual active learning, (ii) the knowledge in immunology is challenging to deliver when students have different backgrounds. This concern is why this study made a video followingthe "simple and practical" principle. Thus, the students could gain knowledge step-by-step from basic principles, procedures of the test, results, interpretations, and the advantage of the test in clinical immunologyapplication,finally (iii)Thai students are generally shy to ask questionsin class. Students in this study were divided into small groups during the face-toface learningto join the active exploration in laboratory demonstration (students:lecture ratio $=10: 1$ ). This character could motivate them to participate in the discussion and problem-solving in thein-class learning activity, as successfully demonstrated in the application of SPOC and team-based learning for dermatology and venereology studies [32].Therefore, these results suggested that learning technologies as SPOC combined with flipped

Page $12 / 21$ 
classrooms complemented each other. However, the implication from this study could serve as a reference for further medical technology educations. For further studies, construction and application of SPOC-based flipped classroom teaching model in immunology course should be contributed based onoutcome-based education for bigger class sizeto check the validity of data collection or the better enhancement of the SPOC-based flipped classroom pedagogy.

\section{Conclusions}

There has been lessresearch on implementingthe SPOC-based flipped classroom method in medical technology education. This studyintroduced it in a basic immunology course. The findings confirmed that this teaching model effectively encouraged students'learning improvementand positively impacted their learning perceptions and motivations on basic immunology study. However, the SPOC based flipped classroom mode still needsdevelopment, and the effectiveness needs to be verified in teaching practice over an extended period.Thisinnovative exploration has provided a new perspective for curriculum reform in medical technology, and it believes that medical technology education will have a qualitative leap in the future.

\section{Abbreviations}

SPOC

Small Private Online Course

CT

conceptual test

$\mathrm{MU}$

Mahidol University

$\mathrm{RQ}$

Research Question

PU

Perceived Usefulness

$\mathrm{PE}$

Perceived Ease of Use

AT

Attitude

$\mathrm{BI}$

Behaviour Intention

IM

Intrinsic Motivation

EM

Extrinsic Motivation

CM

Career Motivation

SDT

Self-Determination

SEF

Self-Efficacy 
AA

Assessment Anxiety

M

Mean

SD

Standard Deviation.

\section{Declarations}

\section{Ethics approval and consent to participate}

All methods in this study were carried out according to relevant guidelines and regulations. Ethical approval all procedures performed in the studies involving human participants were in accordance with the ethical standards of the Mahidol University Central Institutional Review Board, Thailand, with the COA No. MU-CIRB 2019/158.0710 declaration and its later amendments or comparable ethical standards. Informed consent was obtained from all individual participants included in the study.

\section{Consent for publication}

Not applicable.

\section{Availability of data and materials}

The data are kept at the Department of Clinical Microbiology and Applied Technology, Faculty of Medical Technology, Mahidol University, Thailand. The datasets used and/or analyzed during the current study are available from the first author on reasonable request. Any questions or requests regarding the data can be addressed to Somying Loharungsikul (somying.loh@mahidol.ac.th).

\section{Competing interests}

The authors declare that they have no competing interests.

\section{Funding}

No funding

\section{Authors' contributions}

SL contributed to the development of the study, data collections, and the manuscript's writing, reviewing, and finalizing.KE is responsible for creating the figures and table. PNcritically revised all versions of the manuscript. PP contributed to the conception and designedthe study,analyzed thedata,and manuscript preparation.All authors have approved the revisions of the manuscript and agreed to the publication of the final manuscript.

\section{Acknowledgements}

The authors would like to thank all 81medical technology students for their participation and our immunological team lecturersfor their support during the investigation. Special thanks to Asst.Prof. Chaniya Leepiyasakulchaifor 
providing a course-related implementation.This study was supported by the Division of Academic Affairsand Faculty of Medical Technology, Mahidol University, Thailand.

\section{Authors' information}

Somying Loharungsikul, SL, is currently anassistant professor and an immunology lecturer at the Department of clinical microbiology and applied technology, Faculty of Medical Technology, Mahidol University, Thailand. She is interested in technology-enhanced medical technology education.

Kawitsara Eumbunnapong, KE,is currently anacademic in medical media production atthe Faculty of Medicine Siriraj Hospital, MahidolUniversity, Thailand.She is interested in producingmedical instructional materials, medical drawing,patient imaging, and technology for education.

Prachyanun Nilsook, PN,is a professor at the Division of Information and Communication Technology for Education, Faculty of Technical Education, King Mongkut's University of Technology North Bangkok, Thailand.He specializesin the field of educational technology and instructional design.

Patcharin Panjaburee, PP, is an associate professor at Institute for Innovative Learning Mahidol University, Thailand. She is interested in designing and developing digital learning such as mobile and ubiquitous learning, digital game-based learning in Computer Science and Mathematics, and designing and developing a personalized e-learningsystem in subject areas.

\section{References}

1. French H, Arias-Shah A, Gisondo C, Gray MM. Perspectives: the flipped classroom in graduate medical education. Neoreviews. 2020;21(3):e150-6. https://doi.org/10.1542/neo.21-3-e150.

2. Fatima SS, Arain FM, Enam SA.Flipped classroom instructional approach in undergraduate medical education.Pak J Med Sci.2017;33(6):1424-28.https://doi.org/10.12669/pjms.336.13699.

3. Angadi NB, Kavi A, Shetty K, Hashilkar NK.Effectiveness of flipped classroom as a teaching-learning method among undergraduate medical students - An interventional study.J Edu Health Promot. 2019;8:211.https://doi.org/10.4103/jehp.jehp_163_19.

4. Morgan H, McLean K, Chapman C, Fitzgerald J, Yousuf A, Hammoud M.The flipped classroom for medical students.Clin Teach. 2015;12(3):155-60.https://doi.org/10.1111/tct.12328.

5. Chowdhury TA, Khan H, Druce MR, Drake WM, Rajakariar R, Thuraisingham R,Dobbie H, Parvanta L, Chinegwundoh F, Almushatat A, Warrens A, Alstead EM.Flipped learning: Turning medical education upside down.Future Healthc J. 2019; 6(3):192-5. https://doi.org/10.7861/fhj.2018-0017.

6. Tang F, Chen C, Zhu Y, Zuoa C, Zhonga Y, Wanga N, Zhou L, Zou Y, Liang D.Comparison between flipped classroom and lecture-based classroom in ophthalmology clerkship.Med Edu Online. 2017;22(1):1395679.https://doi.org/10.1080/10872981.2017.1395679.

7. Ruiz-Palmero J, Fernández-Lacorte JM, Sánchez-Rivas E, Colomo-Magaña E.The implementation of Small Private Online Courses (SPOC)as a new approach to education.Int J Educ Technol High Educ. 2020;17:27.https://doi.org/10.1186/s41239-020-00206-1.

8. Wang XH, Wang JP, Wen FJ, Wang Jun, Tao JQ.Exploration and practice of blended teaching model based flipped classroom and SPOC in higher university.J Educ Pract. 2016;7(10):99-104. 
9. Zhou J, Yu H, Chen B, Mai C, Yu L.The construction of teaching interaction platform and teaching practice based on SPOC mode.In: 11th Inter-national Conference on Computer Science Education (ICCSE 2016).Nagoya: IEEE Publisher; 2016. https://doi.org/10.1109/ICCSE.2016.7581596.

10. Lockhart BJ, Capurso NA, Chase I, Arbuckle MR, Travis MJ, Eisen J, Ross DA.The use of a small private online course to allow educators to share teaching resources across diverse sites:the future of psychiatric case conferences?.Acad Psychiatry. 2017;41(1):81-5.https://doi.org/10.1007/s40596-015-0460-4.

11. Zhang XM, Yu JY, Yang Y, Feng CP, Lyu J, Xu SL.A flipped classroom method based on a small private online course in physiology.Adv Physiol Educ. 2019;43(3):345-49.https://doi.org/10.1152/advan.00143.2018.

12. Vavasseur A, Muscari F, Meyrignac O, Nodot M, Dedouit F, Revel-Mouroz P, Dercle L.Blended learning of radiology improves medical students' performance, satisfaction, and engagement.Insights Imaging. 2020;11:61. https://doi.org/10.1186/s13244-020-00865-8.

13. Cong D, Xiaoyan D, Meishuang L, Qiang Z.Application of the flipped classroom teaching mode based on small private online course on laboratory test of clinical hematology.Chin J Med Edu. 2021;41(5):407-11.

14. Bian H, Bian Y, Li J, Li Y, Ma Y, Shao X, Xu J.Peer instruction in a physiology laboratory course in China.Adv Physiol Educ. 2018;42:449-53.https://doi.org/10.1152/advan.00153.2017.

15. Huang HL, Chou CP, Leu S, You HL, Tiao MM, Chen CH. Effects of a quasi-experimental study ofusing flipped classroom approach to teachevidence-based medicine to medicaltechnology students.BMC Med Educ.2020;20:3. https://doi.org/10.1186/s12909-020-1946-7.

16. Vaysse C, Chantalat E, Beyne-Rauzy O, Morineau L, Despas F, Bachaud J, et al. The Impact of a small private online course as a new approach to teaching oncology: development and evaluation. JMIR Med Educ. 2018;4(1):e6. https://doi.org/10.2196/mededu.9185.

17. Teo T.Modelling technology acceptance in education: A study of pre-service teachers.Comput Educ. 2009;52(2):302-12.

18. Glynn SM,Koballa TRJr.Motivation to learn in college science. In Mintzes JJ, Leonard WH, editors. Handbook of college science teaching.Arlington:National Science Teachers Association Press; 2006p. 25-32.

19. Pang H, Li S, Wang J, Zhang Y, Li L.Relying on the SPOC platform to flipping medical immunology classroom teaching.Chinese J Med Educ Res. 2018;12:1219-23.

20. Ruiz-Palmero J, Fernández-Lacorte JM, Sánchez-Rivas E, Colomo-Magaña E.The implementation of Small Private Online Courses (SPOC)as a new approach to education.Int J Educ Technol High Educ. 2020;17:27.https://doi.org/10.1186/s41239-020-00206-1.

21. Lou J, Zheng P, Jiang C.The Enlightenment of SPOC on Teaching Reform of Higher Education in China-Based on the Perspective of Mastery Learning Theory.Science J Educ.2016;4(2):95100.https://doi.org/10.11648/j.sjedu.20160402.22.

22. Gielen G.Advantages and Disadvantages of SPOCs (Small Private Online Courses):Experiences with OnlineLearning.In: Proceedings of the European Distance and E-Learning Network (EDEN 2016). Budapest: EDEN.org; 2016.https://doi.org/10.38069/edenconf-2016-ac-0014.

23. Srisuwan C,Panjaburee P.Implementation of flipped classroom with personalised ubiquitous learning support system to promote the university student performance of information literacy.Int J Mob Learn Organ. 2020;14(3):398-424.https://doi.org/10.1504/IJML0.2020.108200.

24. Lai CL, Hwang GJ.A self-regulated flipped classroom approach to improving students' learning performance in a mathematics course.ComputEduc.2016;100(1):126-40. 
25. Ma W, Luo Q. Pedagogical practice and students' perceptions of fully online flipped instruction during COVID19. Oxf RevEduc. 2021. https://doi:10.1080/03054985.2021.1994382.

26. Wang S, Xu X, Li F, Fan H, Zhao E, Bai J.Effects of modifed BOPPPS-based SPOCand Flipped class on 5th-year undergraduateoral histopathology learning in Chinaduring COVID-19.BMC Med Educ. 2021;21:540.https://doi.org/10.1186/s12909-021-02980-6.

27. Tang X.An empirical study of a SPOC embedded flipped classroom model for college intercultural communication course: perceptions of students.In: Asian Conference on Language Learning (ACLL 2019).Tokyo: Official Conference Proceedings; 2019.

28. Rodriguez MF, CorreaJH, Perez-Sanagustin M,Pertuze J, Alario- Hoyos C.A MOOC-Based Flipped Class:Lessons Learned from the Orchestration Perspective.In: 5th European Conference on Massive Online Courses(EMOOCs 2017).Madrid: Springer-Verlag; 2017.

29. Kastrati Z, Kurti A, Hagelbäck J.The effect of a flipped classroom in a SPOC:students' perceptions and attitudes.In: 11th International Conference on Education Technology and Computers(ICETC 2019).

Amsterdam:ACM; 2019.https://doi.org/10.1145/3369255.3369304.

30. Thongkoo K, Panjaburee P, Daungcharone K.Integrating inquiry learning and knowledge management into a flipped classroom to improve students' web programming performance in higher education.KMEL. 2019;11(3): 304-24.

31. Chen J,Zhou J, Wang Y, Qi G, Xia C, Mo G, Zhang Z. Blended learning in basic medical laboratory courses improves medical students' abilities in self-learning, understanding, and problem solving. Adv Physiol Educ. 2020;44:9-14.https://doi.org/10.1152/advan.00076.2019.

32. Zeng J, Liu L, Tong X, Gao L, Zhou L, Guo A, Tan L. Application of blended teaching modelbased on SPOC and TBL in dermatologyand venereology. BMC Med Educ. 2021;21:60.https://doi.org/10.1186/s12909-021-030427.

\section{Figures}


Login to online course platform of Mahidol University

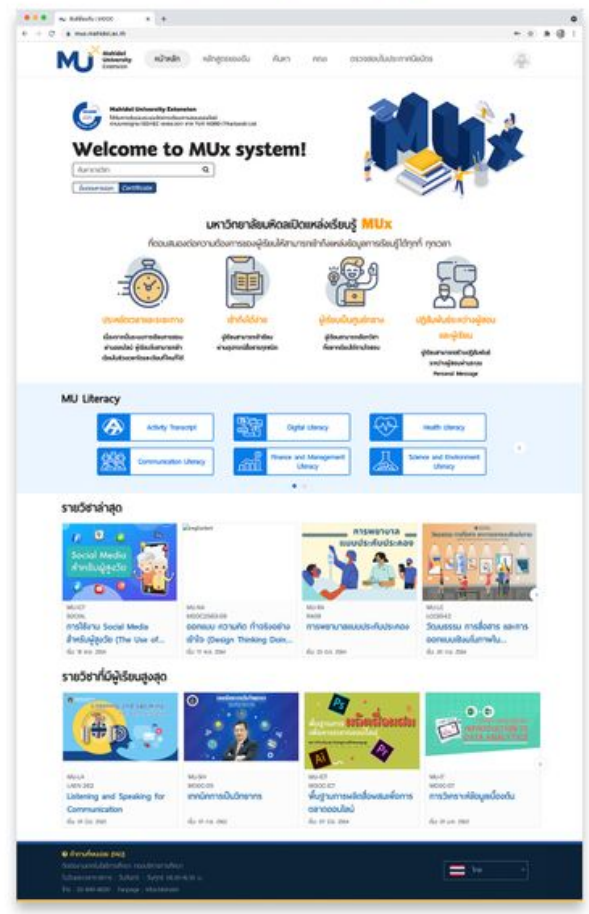

SPOC course
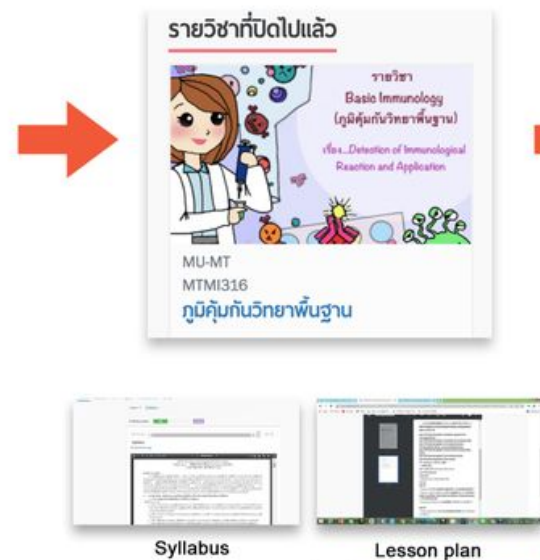

Syllabus

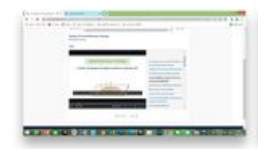

Infografic video

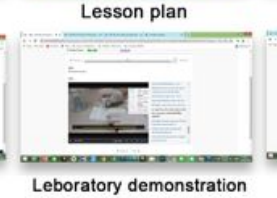

Leboratory demonstration

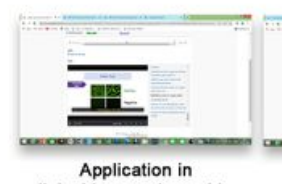

Application in clinical immunology video
Courseware

(6 Topics for self-learning)
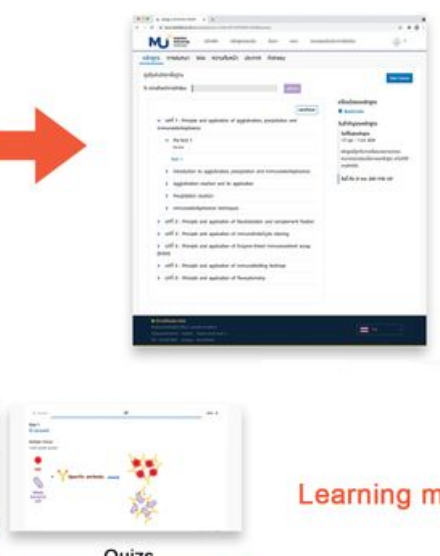

Learning materials

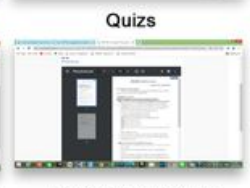

Laboratory protocol
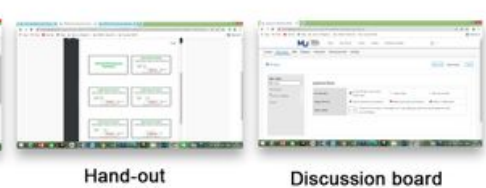

\section{Figure 1}

Registration tothe SPOC on Mahidol University Extension 
Pre-class

Teacher introduce course and learning system

$\downarrow$

SPOC : Self online learning platform

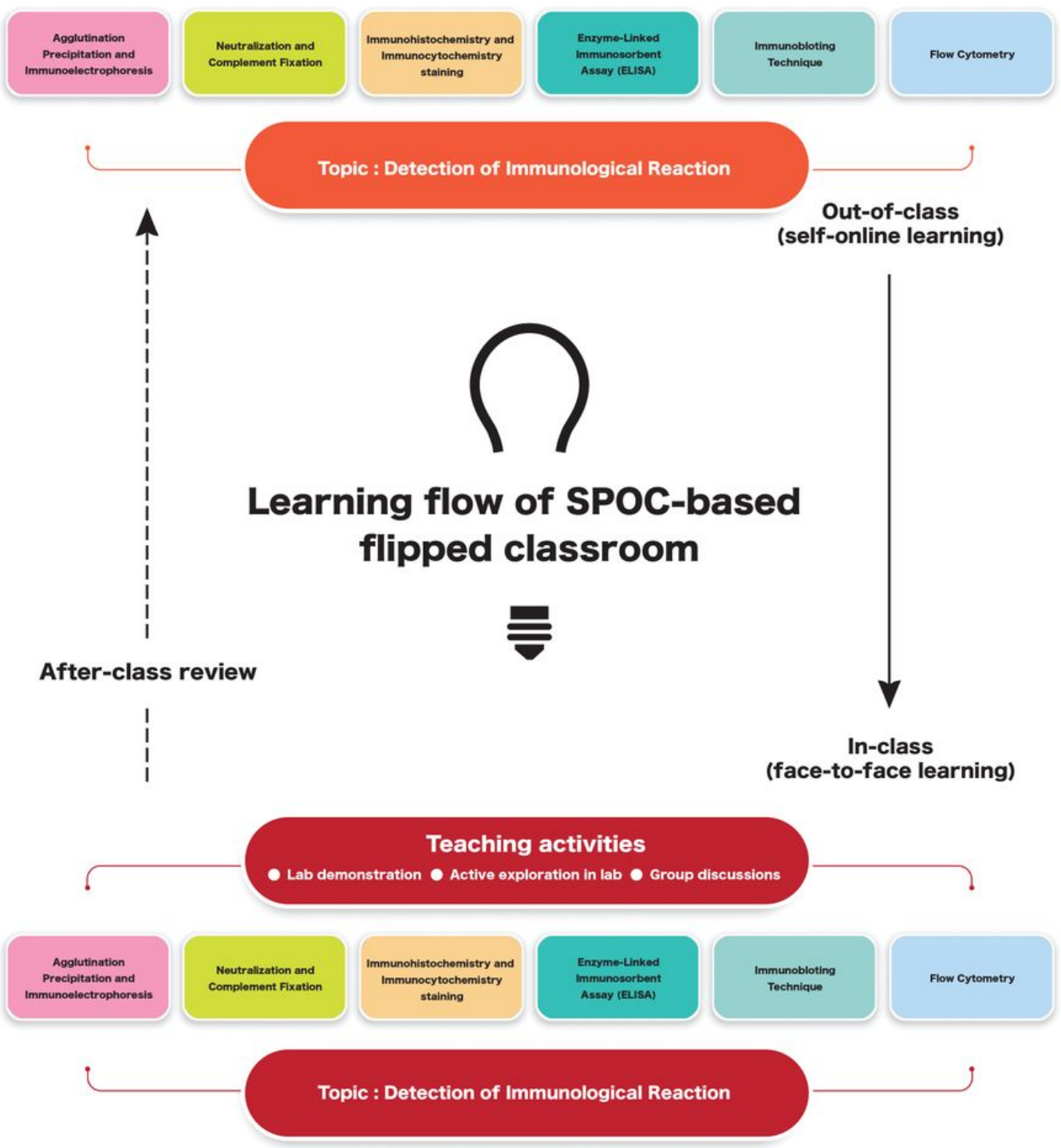

Figure 2

Learning flow of SPOC-based flipped classroom 
SPOC

(Self-online learning platform)
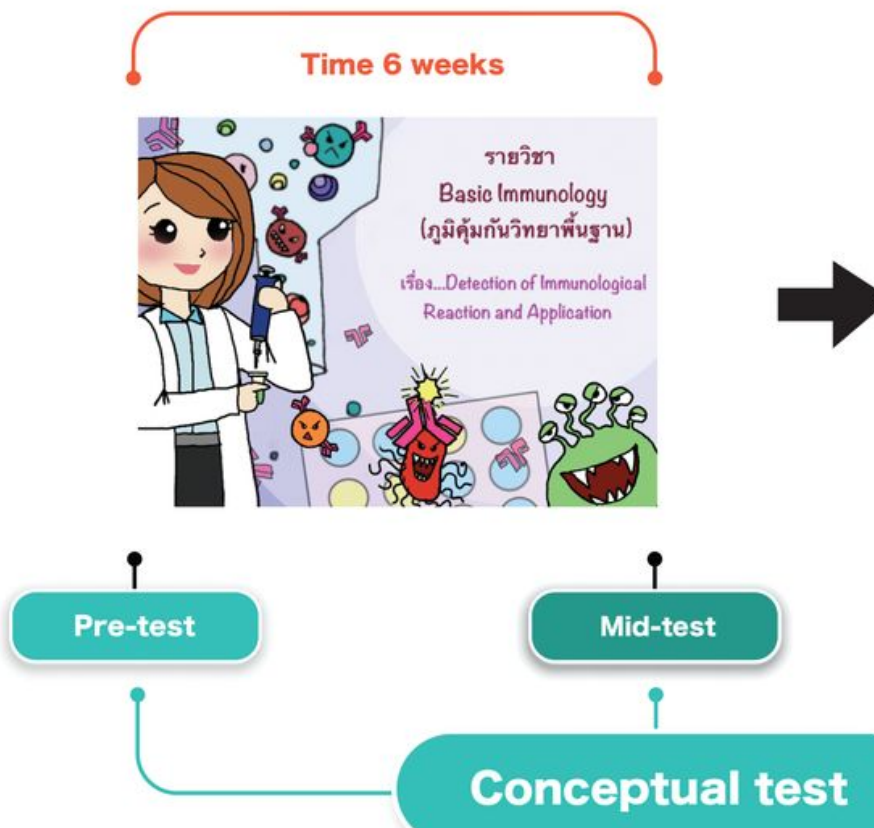

Figure 3

Procedure for data collection inSPOC-based flipped classroom

\section{Conceptual test}

\section{In-class activities \\ (face-to-face learning)}

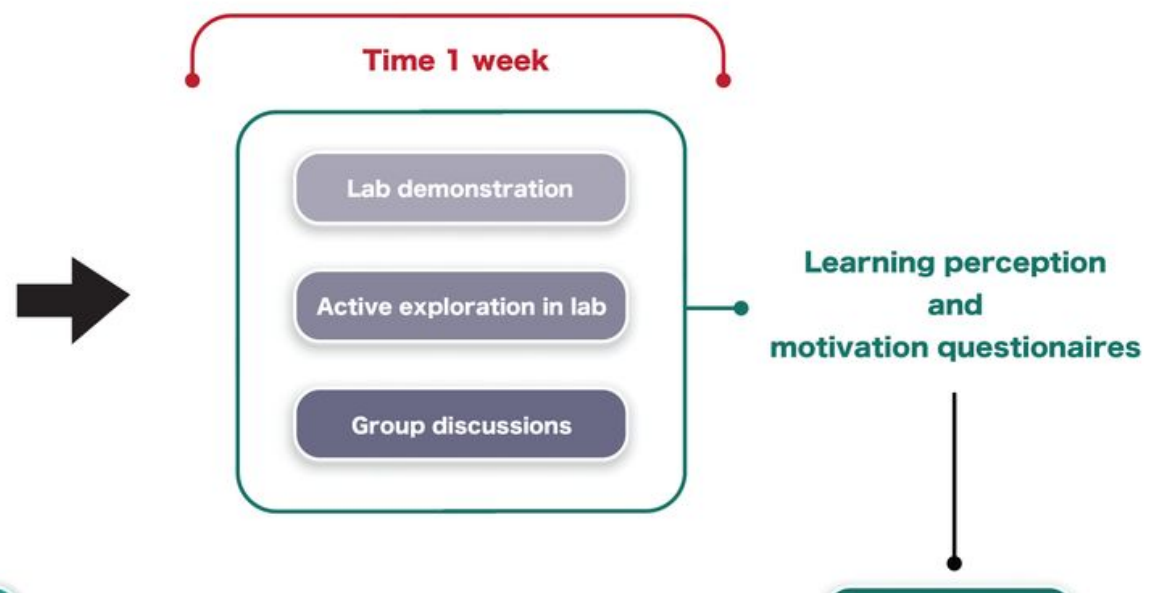

Post-test 


\section{Estimated Marginal Means of Test}

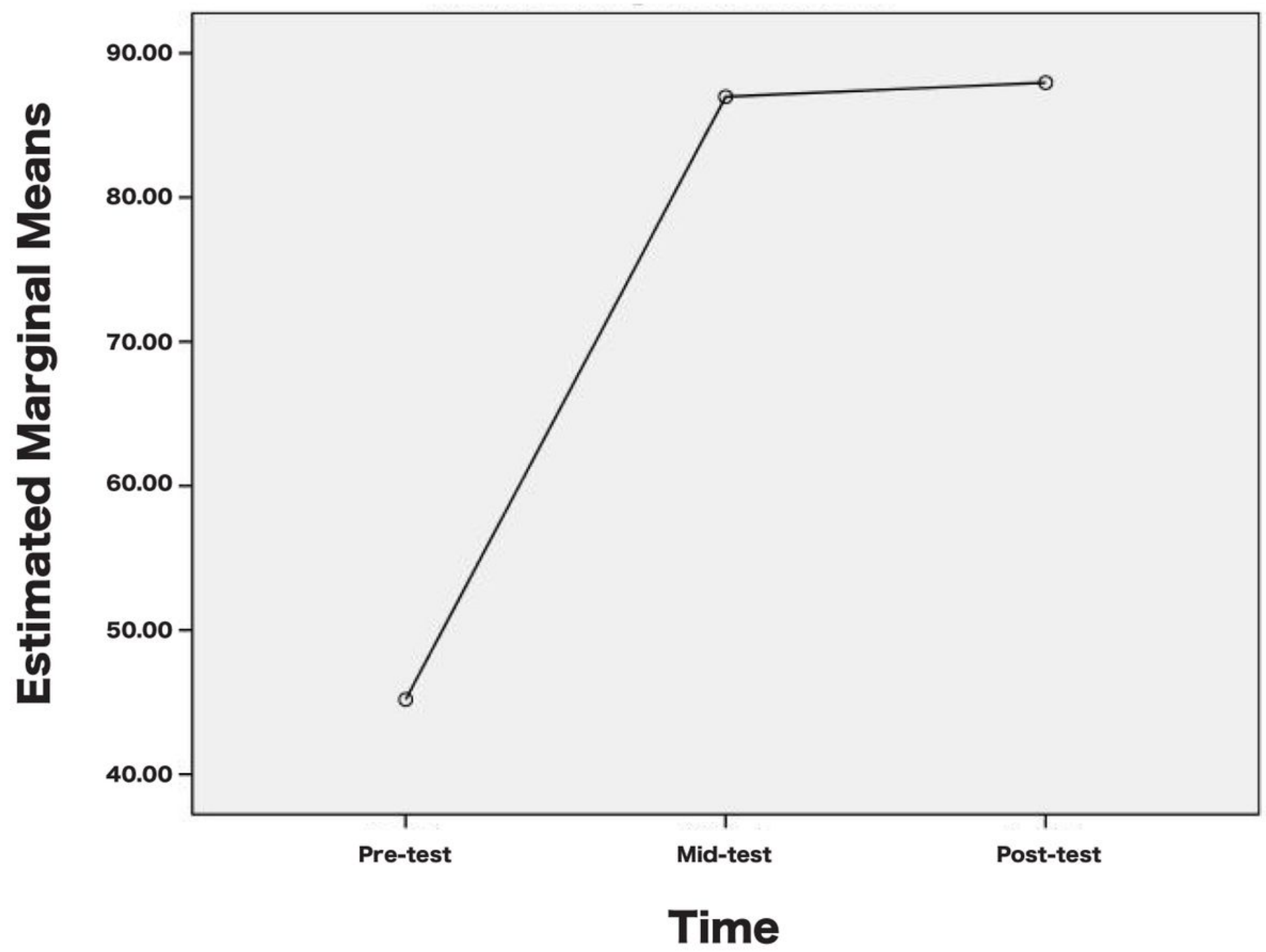

Figure 4

Plots of repeated-measures and pairwise comparisons of the three times

\section{Supplementary Files}

This is a list of supplementary files associated with this preprint. Click to download.

- TestingScoresQuestionnaireRatingsSL27July2020.xIsx 